\title{
OPTIMIZATION OF A SOLAR HYDROGEN STORAGE SYSTEM: SAFETY CONSIDERATIONS
}

\author{
E. López, F. Isorna, F. Rosa \\ Instituto Nacional de Técnica Aeroespacial \\ Ctra. S. Juan- Matalascañas, km. 34, 21130 Mazagón (Huelva) - SPAIN
}

\begin{abstract}
Hydrogen has been extensively ssed in many industrial applications for more than 100 years, including production, storage, transport, delivery and final use. Nevertheless, the goal of the hydrogen energy system implies the use of hydrogen as an energy carrier in a more wide scale and for a public not familiarised with hydrogen technologies and properties.
\end{abstract}

The road to the hydrogen economy pass by the development of safe practices in the production, storage, distribution, and use of hydrogen. These issues are essential for hydrogen insurability. We have to bear in mind that a catastrophic failure in any hydrogen project could damage the insurance public perception of hydrogen technologies at this early step of development of hydrogen infrastructures.

Safety is a key issue for the development of hydrogen economy, and a great international effort is being done by different stakeholders for the development of suitable codes and standards concerning safety for hydrogen technologies [1,2].

Additionally to codes and standards, different studies have been done regarding safety aspects of particular hydrogen energy projects during the last years[3,4]. Most of them have been focused on hydrogen production and storage in large facilities, transport, delivery in hydrogen refuelling stations, and utilization, mainly on fuel cells for mobile and stationary applications. In comparison, safety considerations for hydrogen storage in small or medium scale facilities, as usual in hydrogen production plants from renewable energies, have received relatively less attention.

After a brief introduction to risk assessment for hydrogen facilities, this paper reports an example of risk assessment of a small solar hydrogen storage system, applied to the INTA Solar Hydrogen Production and Storage facility as particular case, and considers a top level Preliminary Failure Modes and Effects Analysis (FMEA) for the identification of hazard associated to the specific characteristics of the facility.

Keywords: hydrogen storage, renewable energy, safety, FMEA

\section{INTRODUCTION TO HYDROGEN FACILITIES RISK ASSESSMENT}

Widespread use of hydrogen is just a question of time. Nevertheless, several technical, economic and societal barriers must be overcome prior to this generalized utilization. One of the most important barriers is the development of suitable hydrogen storage and delivery systems, produced from diverse sources, e.g. renewable energy, and intended for diverse uses. These are key elements of the hydrogen economy. Flexible use of hydrogen as an energy carrier energy needs proper means to store it for later use, to transport it from the point of production to the use point of use, and to charge and discharge it conveniently as needed.

Intermittent nature of renewable energy, mainly solar and wind, supposes an important barrier to the objective of achieving a high penetration level of such energies in the short and medium term energy scenario [reference]. In order to solve these problems, several option for energy storage have been considered to provide load-levelling mechanisms for the cyclic renewable energy production from renewable sources, mainly wind and solar. One of the most promising is the storage of energy in form of hydrogen, due to flexibility of this energy carrier, and its potential use in stationary fuel cell and vehicles $[5,6,7]$.

Several criteria must be taken into account during the design, building-up, operation and maintenance of hydrogen storage systems, both for automotive or stationary applications. 
Traditionally, such criteria have been based on conventional parameters like technical performance, energetic efficiency, availability, economic and technical viability, health and safety implications, etc.

Hydrogen production from renewable energy requires suitable hydrogen storage systems, and safety requirements must play an important role in the choice of most adequate solution for each project. The goal of this risk assessment will be to improve the new design with a systematic approach to the identification and assessment of potential hazards and specific risk factors in the production and storage of hydrogen from renewable energy, in order to minimize the risks associated to such facilities and helping to the development of these energy storage technologies.

Safety evaluation can be done by safety analysis methods that comprise a systematic study of the structure and function of the process plant system, an identification of potential accident contributors, an evaluation of the risk presented by them, and a search of risk-reducing measures. Quantitative risk analysis (QRA) is one of such methods, providing a quantitative tool to evaluate risk and to identify areas for cost-effective risk reduction. Figure 1 shows different steps involved in a QRA.

\section{Quantitative Risk Assessment}

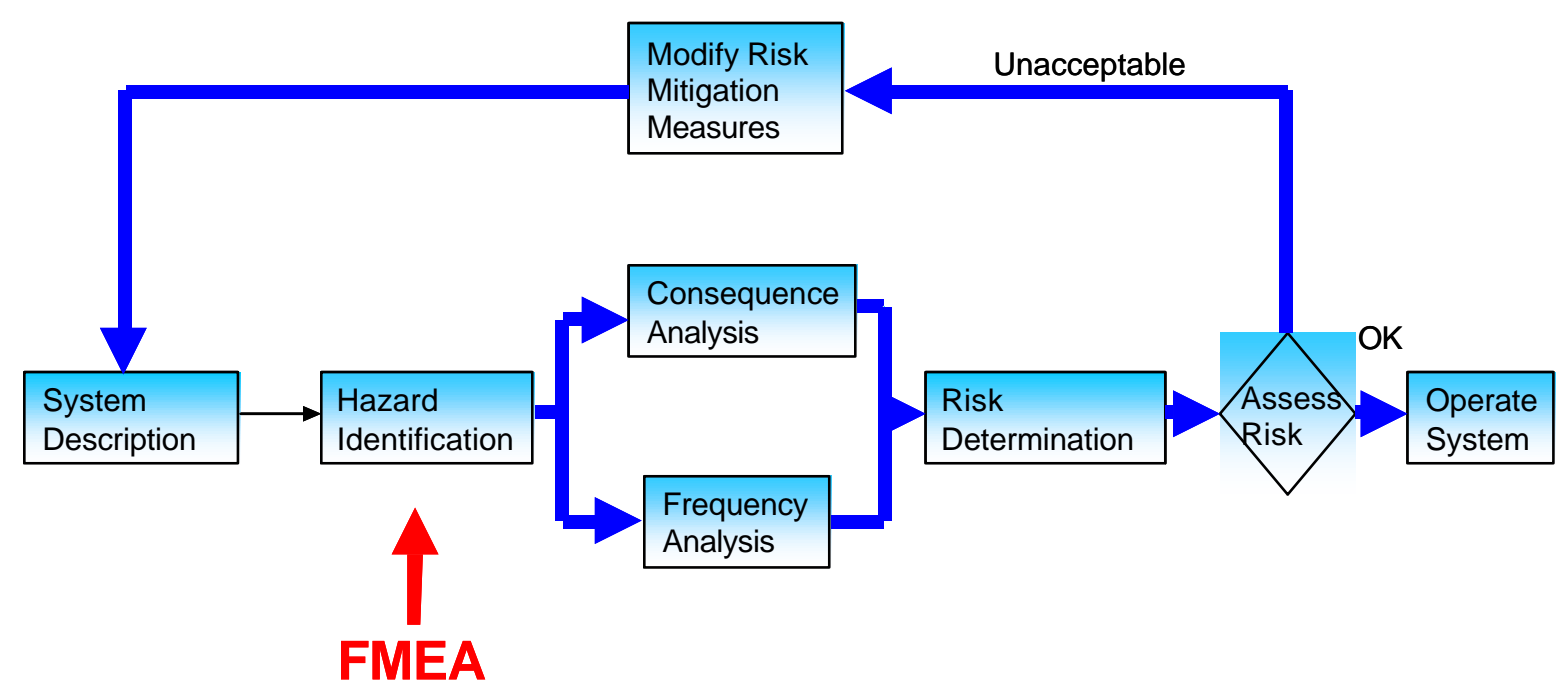

Figure 1: Typical structure of a Quantitative Risk Assessment

Hazard identification is the most important step in risk analysis, because final results for risk assessment will depend on the accuracy and care taken at this step. In the design stages of hydrogen demonstration projects, the goal of hazard identification will be the identification and analysis of all potential hazards in hydrogen production, delivery, utilization, or storage, as well as any system aspects that may be adversely affected by a failure and could be considered like threats or impacts to personnel, both employees or public, equipment, environment, etc.

Hazards identification tray to answer the question, "what can go wrong?". It includes some systematic methods like failure mode effect analysis (FMEA), hazard and operability (HAZOP), "What-if" analysis, checklist analysis, fault tree analysis, event tree analysis, Probabilistic Risk Assessment (PRA), etc.

Failure Modes and Effects Analysis (FMEA) is a widely used tool to identifying significant safety concerns in advance, before the project is fully implemented. A FMEA is a systematic and structured method of identifying product and process problems, assessing their significance, 
and identifying potential solutions that reduce their significance. The objective of a FMEA is to look for all the ways a product or process can fail (failure modes). Each failure mode has a cause and a potential effect. Some failure modes are more likely to occur than others, and each potential effect has a relative risk associated with it. The FMEA process is a way to identify the failure modes within a process or product and to identify actions to reduce the severity, occurrence, or eliminate the cause of the failure mode. In a FMEA, the relative risk of a failure and its effect is determined by the occurrence of an event, by its severity and by the probability of detection, i.e. the probability of the failure being detected before the impact of the effect is realized.

In general, the FMEA process follows a standard procedure, identifying top level hazards/events, related equipment/components/processes, potential failure modes and effects, design inherent safety and potential prevention and/or mitigation corrective actions. A FMEA can be performed via two different approaches. The hardware, or component, analysis identifies component failures in a bottoms-up approach. On the other hand, the functional approach is a top-down method, starting at the system level. This is more suitable when specific components have not yet been chosen or there is not detailed information about equipment.

\section{INTA SOLAR HYDROGEN STORAGE FACILITY}

This facility was built up in the period 1992-1996, and its original design included passive and active safety measures, as recommended by good engineering practices that address safety concerns and general regulations for hydrogen facilities, but not a specific risk assessment was done. Nevertheless, during the operation period, additional safety recommendations from international standards have been taken into consideration [8]. At present, the plant is being redesigned, adding to the existing PV field a small windmill and connecting both power generation systems to an alkaline electrolyzer. The hydrogen storage unit will be also modified with the addition of a high pressure hydrogen dispenser to refuel a fuel cell vehicle.

This facility is coupled with a solar hydrogen production plant and was built up in the mid 90's. Hydrogen production plant includes an $8.5 \mathrm{kWp}$ P.V. field connected to a $5.2 \mathrm{~kW}$ alkaline electrolyzer. Table 1 shows main characteristics of this production plant.

Table 1: Solar Hydrogen Production Plant Characteristics

* Photovoltaic Field:

- $8.5 \mathrm{~kW}_{\mathrm{p}}$ at $1000 \mathrm{~W} / \mathrm{m}^{2}$ and $25 \stackrel{\circ}{\circ} \mathrm{C}$ cell temperature

- 144 BP solar modules ( mod. BP 260S)

- Flexible topology

* Electrolyzer:

- $5.2 \mathrm{~kW}$ at nominal $108 \mathrm{~A}$ and $48 \mathrm{v}$

- $\mathrm{H}_{2}$ production: $1.2 \mathrm{Nm}^{3} / \mathrm{h}$

- $\mathrm{H}_{2}$ purity: $99.7 \% \pm 0.1 \% \mathrm{vv}$

- Operational conditions: 6 bar, $80 \stackrel{\circ}{\mathrm{C}}, 30 \% \mathrm{KOH}$

To store produced hydrogen, two different storage systems have been chosen: metal hydride and pressurized gas. Both system are interconnected, so the gas stored in the hydride container can be compressed and stored in bottles at 200 bars. Both systems have common devices like purification unit, an intermediate buffer, etc.

Hydride container can be used like an other intermediate buffer of the pressurized gas system, and consider one single storage system that integrates the pressurized gas subsystem and the metal hydride subsystem. Hydrogen can be stored in pressurized gas form or in metal hydride depending on the production rate, availability of cold water or hot water, availability of air driven, etc. Both systems will be evaluated from an economic and energetic point of view, in order to find the best option of hydrogen storage for small solar electrolytic facilities. 
Main design parameters for INTA solar hydrogen storage facility were as follow:

- Hydrogen production rate: $1.2 \mathrm{Nm}^{3} / \mathrm{h}$

- Hydrogen storage capacity: enough for an operation week (25-30 $\left.\mathrm{Nm}^{3}\right)$

- $\quad$ Operation during 48 weeks per year

- $\quad$ Charging cycles number higher than discharging cycles number

- $\quad$ Availability and reasonable cost for small facilities

- Other requirements: availability, auxiliary systems, etc.

Three different sections can be considered in the INTA solar hydrogen storage system:

- $\quad$ Low pressure storage area

- $\quad$ Metal hydride area

- $\quad$ Compression and high pressure storage area

The low pressure storage area consists in a 1000 । of nominal capacity intermediate buffer located after the purification unit and the electrolyzer. Thus maximum operation pressure at the electrolyzer is 6 bar, maximum hydrogen capacity of intermediate buffer will be approximately 6 $\mathrm{Nm}^{3}$.

Solar hydrogen nominal production is around $1 \mathrm{Nm}^{3} / \mathrm{h}$, and after a day of operation form sunrise to sunset the intermediate buffer is full, so that hydrogen pass to metal hydride area, compression and high pressure storage area or is used directly in the fuel cell facilities existing in the laboratory.

Metal hydride area includes the metal hydride container, the cooling/heating water supply system and several sensors for data acquisition. The hydride storage container comprises a pressurized tank filled with metallic hydride material, a cooling/heating shell, water supply and hydrogen supply provided with safety and shut-off valves. Table 2 summarizes the main characteristics of this metal hydride container. Hydrogen supplied by the metal hydride container during the discharging process can be compressed at high pressure or used directly in fuel cells.

Table 2: Metal Hydride Container Characteristics

- hydride type: based on $\mathrm{TiMn}_{2}$

- nominal capacity: $24 \mathrm{~m}^{3}$ hydrogen

- designed pressure: max. 10 bar $\left(80^{\circ} \mathrm{C}\right)$

- discharge pressure: $\min .2$ bar $\left(70^{\circ} \mathrm{C}\right)$

- charge pressure: $\min .2$ bar $\left(15^{\circ} \mathrm{C}\right)$

- container weight: approx. $210 \mathrm{~kg}$.

- hydride weight: approx. $130 \mathrm{~kg}$.

- dimensions: approx. $1600 \times 300 \mathrm{~mm}(\mathrm{H} / \mathrm{D})$

In the compression and high pressure storage area, hydrogen gas coming from intermediate buffer or metal hydride container is compressed and bottled in metallic cylinders at 200 bar. Table 3 summarizes the main characteristics of the components of this area. These components are a two-stage air driven gas booster compressor, an air compressor and a fillingbottles device.

Table 3: Compression And High Pressure Area

* Air driven gas booster compressor:

- type: two units three stage Gas Booster compressor system

- inlet hydrogen pressure: min. 2.6 bar

- outlet hydrogen pressure: max.240 bar

- air driven pressure: min. 6.2 bar 
* Compressed air supply:

- two cylinders, two stages air compressor

- 10 H.P. power

Figure 2 shows the general layout for hydrogen storage system, and the relationship between different components in term of species (hydrogen, cool water, warm water) or energy.

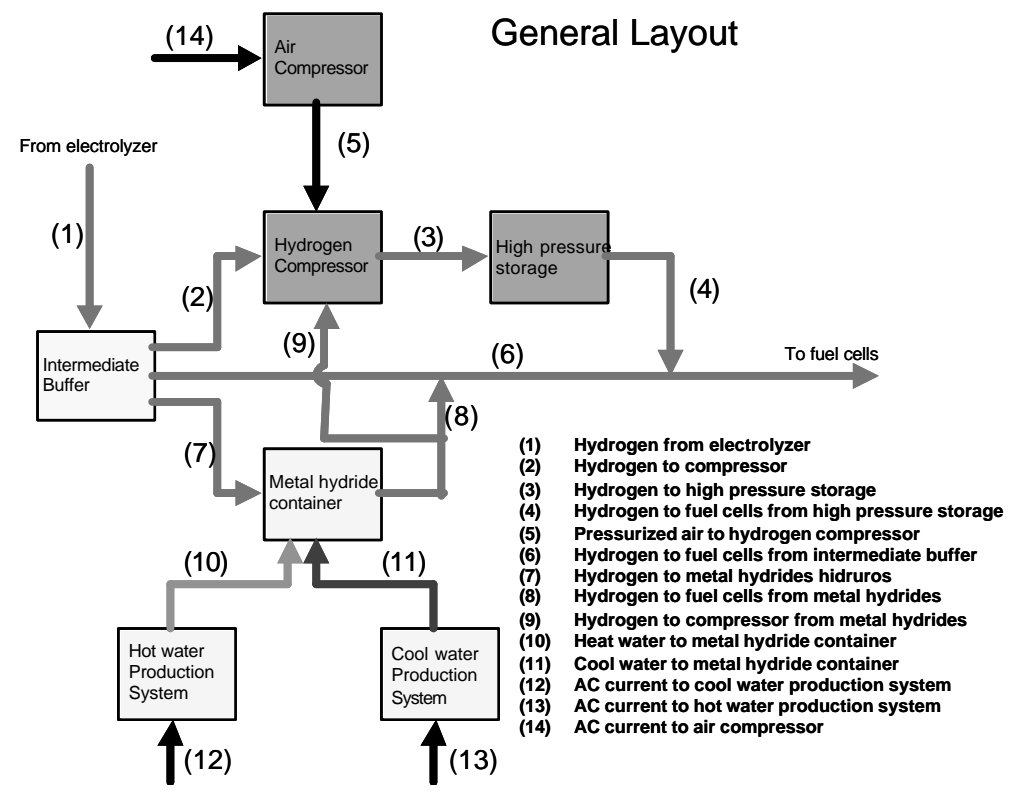

Figure 2: General Layout of Hydrogen Storage System

Figure 3 shows a picture of the facility, with the different areas (low pressure, metal hydride and high pressure area) located in different ventilated rooms.

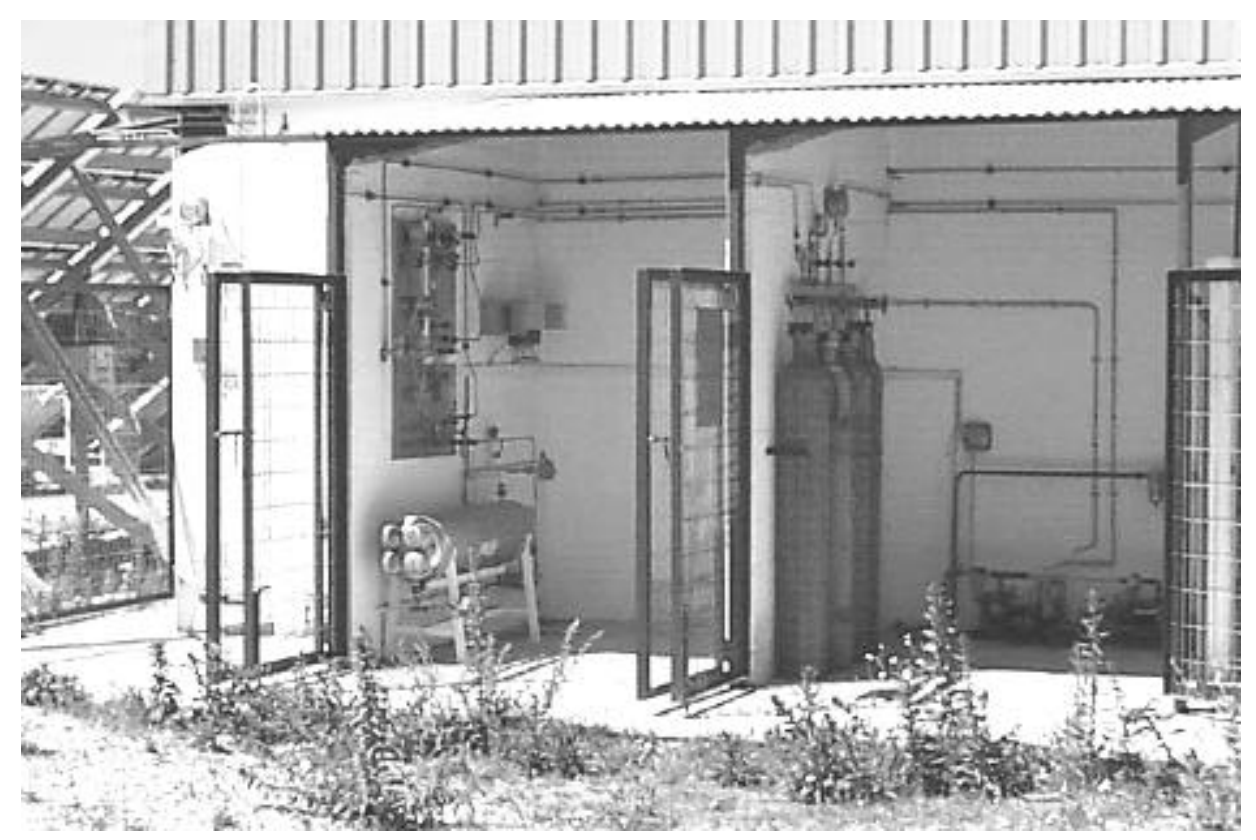

Figure 3: INTA Solar Hydrogen Storage Facility 


\section{FAILURE MODE AND EFFECT ANALYSIS OF INTA HYDROGEN STORAGE FACILITY}

As previous work for the preparation of a full QRA for the updated hydrogen storage facility, including the high pressure hydrogen dispenser, a preliminary top-down high level safety analysis was preformed for the existing facility using the Failure Mode and Effect Analysis technique.

The basis for the analysis was all the available information for such facility, including process flow diagram, piping and instrumentation diagrams, site plan and location, standard operating procedures, safety standards and codes, equipment types, operational data and experience, etc. Good quality hazard identification requires complete information about the system. These data were provided to a team with expertise on various aspects of hydrogen production, storage and delivery systems, including engineering, construction, operation, and the identification of potential failure modes.

The results of the safety analysis are presented in a standard FMEA tabular-format, but at this level, data for consequence and frequency are not considered. In this case, the risk analysis performed could be considered as a "qualitative risk analysis", identifying the most common and minimum set of failure modes that must be of concern from a safety perspective. It is necessary to take into consideration that FMEA is typically part of an overall safety plan, and with its help, the safety plan identifies failure modes for equipment and processes, the consequences of such failures, and evaluation of existing controls and recommendations of additional controls to mitigate the risk of the identified failure modes. The FMEA is an ongoing process and must be updated every time design or process changes are made.

Table 4 shows some examples of FMEA results for low pressure hydrogen storage section.

\begin{tabular}{|c|c|c|c|}
\hline $\begin{array}{l}\text { Process: } \\
\text { Section: } \\
\text { Design intent: }\end{array}$ & $\begin{array}{l}\text { Hydrogen Storage } \\
\text { Low pressure storage } \\
\text { Store up to } 6 \mathrm{Nm3} \text { of hy }\end{array}$ & drogen at 6 bar & \\
\hline No & Failure Mode & Cause & Effects \\
\hline 1 & Storage tank failure & Mechanical failure, corrosion, hydrogen embrittlement & Release of hydrogen. Potential risk of fire or explosion \\
\hline 2 & Piping/valves leak & Mechanical failure & Release of hydrogen. Potential risk of fire or explosion \\
\hline 3 & Charging process fail & Mechanical failure in hydrogen inlet valve, human error & No hydrogen stored. Negative influence on electrolyzer \\
\hline 4 & $\begin{array}{l}\text { Discharging process } \\
\text { fail }\end{array}$ & $\begin{array}{l}\text { Mechanical failure in hydrogen outlet valve, } \\
\text { human error }\end{array}$ & $\begin{array}{l}\text { No hydrogen supply to metal hydride, high pressure } \\
\text { sections nor fuel cells }\end{array}$ \\
\hline 5 & Faulty PRD activation & Defect/Fault in PRD, mechanical failure & Release of hydrogen. Potential risk of fire or explosion \\
\hline 6 & $\begin{array}{l}\text { Overpressure combine } \\
\text { with failure of PRD to } \\
\text { open }\end{array}$ & $\begin{array}{l}\text { Mechanical failure in PRD, } \\
\text { purge line closed }\end{array}$ & Potential risk of catastrophic rupture of the storage unit \\
\hline 7 & $\begin{array}{l}\text { Formation of hydrogen } \\
\text { nitrogen mixtures in } \\
\text { storage tank }\end{array}$ & $\begin{array}{l}\text { Mechanical failure in nitrogen inlet valve, } \\
\text { human operation error }\end{array}$ & $\begin{array}{l}\text { Negative effects on metal hydrides kinetic } \\
\text { Less efficiency in fuel cells }\end{array}$ \\
\hline 8 & Storage tank failure & External fire & $\begin{array}{l}\text { Release of hydrogen. Potential risk of fire or explosion } \\
\text { Potential risk of catastrophic rupture of the storage unit }\end{array}$ \\
\hline
\end{tabular}

Table 4: Low Pressure Hydrogen Storage section FMEA 


\section{CONCLUSIONS}

Potential hazards in INTA Solar Hydrogen Storage plant have been identified and analysed, as well as any system aspects that may be adversely affected by a failure and can involve threats or impacts to personnel, equipment, environment, etc. Failure Modes and Effects Analysis (FMEA) has been the used tool for the identification of significant safety concerns and systemlevel interactions for safety hazards and to demonstrate an understanding and anticipation of component failures.

Three different sections have been considered in the INTA solar hydrogen storage system (low pressure storage area, metal hydride area, compression and high pressure storage area), and FMEA have been applied to each one. The study has been focused on failure modes, causes and effects.

Main conclusions of the analysis show that potential failure modes are mainly container or cylinders failure, piping leaks and valves fails, originated by mechanical or material failure, corrosion or hydrogen embrittlement. Human error has been considered also a potential cause for failure modes in several events. In oder of severity, main effects considered have been slow hydrogen leak, large hydrogen release and catastrophic rupture of the storage unit, with different potential risk of fire or explosion for each event. Different failure modes with no safety hazard, but with influence on system operation and performance have been also identified.

The results of the study have helped to identify a design inherent safety for the new facility, and identify potential prevention and/or mitigation corrective actions, e.g. suitable selection of materials and equipment, correct location of equipment, operating and maintenance procedures, training and qualification for employees, use of hydrogen sensors and implementation of alarms and events in the data acquisition and control system, etc. From this list, the suitable choice of materials and the need of training for personnel are essential for safety purposes, with special emphasis to provide hydrogen safety training for all project personnel responsible for handling equipment containing hydrogen.

\section{REFERENCES}

1. Risk Assessment for Hydrogen Codes and Standards Ohi, James; Moen, Chris; Keller, Jay and Cox, Roger

Proceedings of ICHS 2005, September 8-10, 2005, Pisa

2. ISO/Technical Committee 197 - Hydrogen Technologies status of work

Dey, R.

Proceedings of ICHS 2005, September 8-10, 2005, Pisa

3. Safety Related to the Use of Hydrogen as an Energy Carrier

Andersen V., Paulsen J.L., Markert F.

Proceedings of ICHS 2005, September 8-10, 2005, Pisa

4. Quantitative Risk Analysis Of Gaseous Hydrogen Storage Unit

Brown A.E.P., Nunes E.N., Teruya C.M., Anacleto L.H., Fedrigo J.C., Antoni M.R.D.

Proceedings of ICHS 2005, September 8-10, 2005, Pisa

5. J. Nowotny, C.C. Sorrell, L.R. Sheppard, T. Bak, International Journal of Hydrogen Energy 30 (2005), pages 521-544

6. S. Dunn, International Journal of Hydrogen Energy 27 (2002) , pages 235-264

7. S.R. Vosen, J.O. Keller, International Journal of Hydrogen Energy 24 (1999), pages 1139-1156

8. Basic considerations for the safety of hydrogen systems Technical Report ISO/TR 15916 